\title{
Laparoscopic adrenalectomy for metastatic adrenal cancer with vena cava inferior resection
}

\author{
Nihat Aksakal, Mustafa Tükenmez, Selim Doğan, Orhan Ağcaoğlu, Umut Barbaros, \\ Yeşim Erbil, Rıdvan Seven, Selçuk Özarmağan, Selçuk Mercan \\ Department of General Surgery, Istanbul University Istanbul Faculty of Medicine, Istanbul, Turkey
}

\begin{abstract}
The adrenal glands are a potential site of metastasis for various malignancies. Although laparoscopic adrenalectomy is the gold standard approach for adrenal gland diseases, it is controversial for primary or metastatic adrenal cancers because when adrenal metastases are symptomatic, the adrenal mass is usually adjacent to or has invaded the vena cava inferior ( $\mathrm{VCl}$ ), liver, or kidney. Laparoscopic adrenalectomy is difficult to perform in such cases. Described herein is laparoscopic adrenalectomy for metastatic right adrenal cancer adjacent to $\mathrm{VCl}$. Abdominal magnetic resonance imaging and computed tomography of 66-year-old male patient treated for lung cancer demonstrated mass in right adrenal gland adjacent to IVC. Laparoscopic exploration revealed mass adjacent to $\mathrm{VCI}$. For curative resection, lateral side of VCI was partially resected using endoscopic vascular staples and adrenalectomy was performed. The patient was discharged uneventfully at postoperative third day. Laparoscopic adrenalectomy can be performed safely with endoscopic vascular staples to remove adrenal tumor in patients with cancer, even with invasion of VCl.
\end{abstract}

Keywords: Laparoscopic adrenalectomy; metastatic adrenal carcinoma; vena cava inferior resection.

\section{Introduction}

Even though laparoscopic adrenalectomy has become the gold standard in benign adrenal tumors, still unclear are the indications to laparoscopic adrenalectomy in case of primary or metastatic adrenal malignant lesions. ${ }^{[1,2]}$ Adrenal gland is a common site of metastasis from lung carcinoma. ${ }^{[2,3]}$ Laparoscopic adrenalectomy for metastatic adrenal cancer is technically difficult. Because usually diagnosed at an advanced stage with invasion of or adherence to the liver, kidney, inferior vena cava (VCI), spleen and pancreas. $^{[4,5]}$ We herein present a case of adrenal metastases which was diagnosed during follow-up for lung cancer.

\section{Case Report}

The 66-years-old male patient suffering from lung cancer had no symptom. An abdominal magnetic resonance imaging demonstrated $35 \mathrm{~mm}$ diameter, non-adenomatous mass, adjacent to VCI at right adrenal gland (Figure 1). General physical examination was normal. Laparoscopic adrenalectomy was recommended to the patient whom adrenal function tests were normal. The patient was informed about the operation details. The patient was placed in semi-decubitus position and pneumoperitoneum was obtained by Veress needle. Four $5 \mathrm{~mm}$ to $10 \mathrm{~mm}$ ports were inserted. Laparoscopic exploration revealed a 

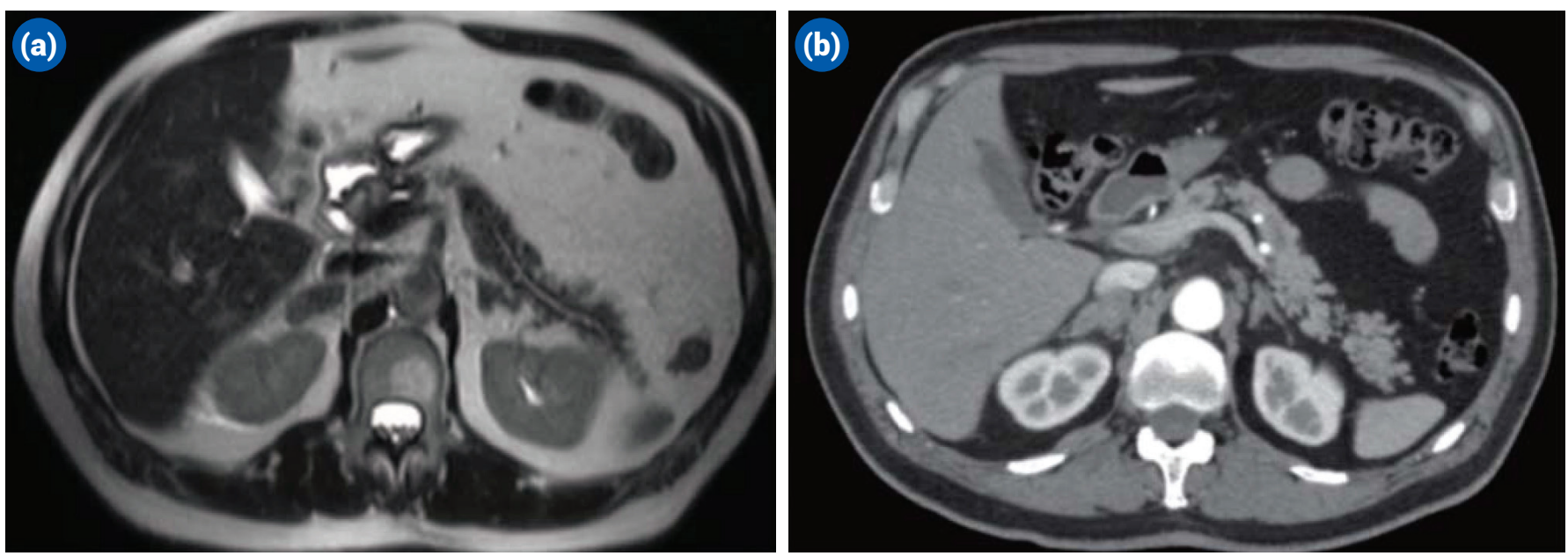

Figure 1. Magnetic resonance imaging (a) and computed tomography (b) scan of patient, showing a non-adenomatous mass adjacent to IVC at right adrenal gland.
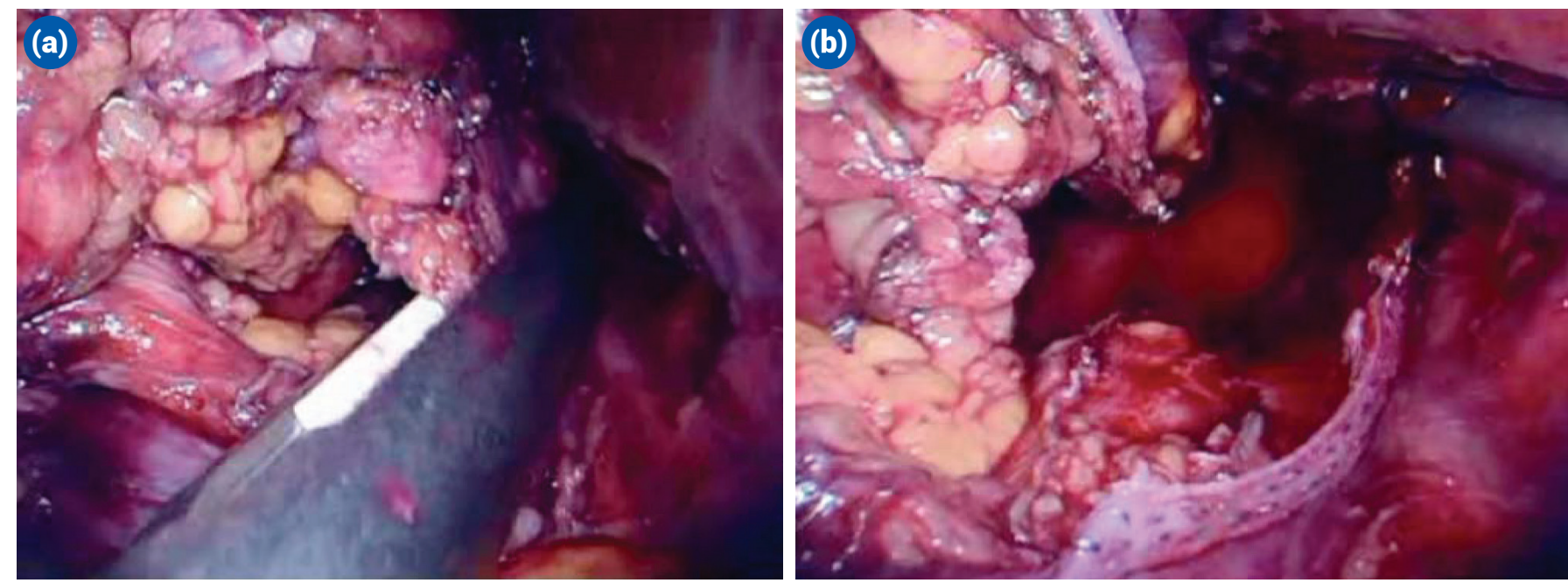

Figure 2. (a, b) Laparoscopic unblock adrenalectomy with partial IVC resection, by using endoscopic vascular staples.

solid mass in right adrenal gland adjacent to IVC. Adrenal gland were dissected and mobilized partially. There were minor adherences to the caval wall. Partial IVC resection was decided for curative treatment. Mass were removed unblock with partial IVC resection, by using endoscopic vascular staples (Figure 2a, b). No peri-operatif complication was occured. Third day after the operation the patient was discharged without any problem. Pathological examination reported adrenal metastasis of lung adenocarcinoma. R0 resection was confirmed pathologically.

\section{Discussion}

Metastastatic adrenal cancers are the second most common type of adrenal mass lesion after adenomas. Adrenal gland is a common site of metastasis from lung carcinoma but rarely the patients are appropriate to a surgical resection. ${ }^{[2,6]}$ Because most cases are diagnosed at an advanced stage, with invasion of or adherence to the liver, kidney and IVC. In patients who present with an isolated adrenal metastasis, adrenalectomy provides to cancer control. Unblock resection is the treatment of choice for adrenal cancer and R0 resection is a strong predictor of longterm survival. ${ }^{[7,8]}$

Laparoscopic adrenalectomy is currently accepted as the gold standard procedure for the treatment of adrenal tumors such as Conn's syndrom, Cushing's syndrome and a pheochromocytoma. But, it is unclear for primary or metastatic adrenal cancer. Laparoscopic adrenalectomy for malignant tumors remains a matter of considerable controversy because the initial published case reports showed the possibility of the procedure generating a peritoneal carcinomatosis or a port site metastasis. ${ }^{[9-11]}$ For this reason, open adrenalectomy was the preferred option for these patients. However, some publications 
have described the use of laparoscopic adrenalectomy for a malignancy with acceptable oncological outcomes. The oncological outcomes from laparoscopic adrenalectomy appears similar to that from open adrenalectomy. ${ }^{[6,9,12,13]}$

Laparoscopic approach may be preferred in some cases. Proper patient selection is very important for the laparoscopic approach. It is important rather remove as a whole with the surrounding fat to provide for R0 resection. If there are no signs definitive invasion, laparoscopic approach may be prefered. Radiologic imaging (magnetic resonance imaging and computed tomography) showed the adrenal mass was adjacent with IVC in our patient. Laparoscopic exploration was planned. There were minor adherences between adrenal mass and caval wall in laparoscopic exploration. Laparoscopic adrenalectomy was decided with partial IVC resection. Adrenal mass as en bloc was removed with partial IVC resection by endoscpic vasculer staples.

Adrenalectomy for metastasis, with intent to prolong survival. Laparoscopic adrenalectomy can be performed with organ confined, adrenal metastasis or primary adrenal carcinoma. Laparoscopic adrenalectomy is a safe and feasible procedure in selected patient for adrenal cancer when performed by a surgeon experienced in laparoscopic and adrenal surgery.

\section{References}

1. Smith CD, Weber CJ, Amerson JR. Laparoscopic adrenalectomy: new gold standard. World J Surg 1999;23:389-96.

2. Lucchi M, Dini P, Ambrogi MC, Berti P, Materazzi G, Miccoli $P$, et al. Metachronous adrenal masses in resected nonsmall cell lung cancer patients: therapeutic implications of laparoscopic adrenalectomy. Eur J Cardiothorac Surg
2005;27:753-6.

3. Schuchert MJ, Luketich JD. Solitary sites of metastatic disease in non-small cell lung cancer. Curr Treat Options Oncol 2003;4:65-79.

4. Luton JP, Cerdas S, Billaud L, Thomas G, Guilhaume B, Bertagna $X$, et al. Clinical features of adrenocortical carcinoma, prognostic factors, and the effect of mitotane therapy. $\mathrm{N}$ Engl J Med 1990;322:1195-201.

5. Albain KS, Crowley JJ, LeBlanc M, Livingston RB. Survival determinants in extensive-stage non-small-cell lung cancer: the Southwest Oncology Group experience. J Clin Oncol 1991;9:1618-26.

6. Uberoi J, Munver R. Surgical management of metastases to the adrenal gland: open, laparoscopic, and ablative approaches. Curr Urol Rep 2009;10:67-72.

7. Kendrick ML, Lloyd R, Erickson L, Farley DR, Grant CS, Thompson GB, et al. Adrenocortical carcinoma: surgical progress or status quo? Arch Surg 2001;136:543-9.

8. Ohwada S, Izumi M, Tanahashi Y, Kawate S, Hamada K, Tsutsumi $\mathrm{H}$, et al. Combined liver and inferior vena cava resection for adrenocortical carcinoma. Surg Today 2007;37:291-7.

9. Eto $M$, Hamaguchi $M$, Harano $M$, Yokomizo A, Tatsugami $\mathrm{K}$, Naito S. Laparoscopic adrenalectomy for malignant tumors. Int J Urol 2008;15:295-8.

10. Suzuki K, Ushiyama T, Mugiya S, Kageyama S, Saisu K, Fujita K. Hazards of laparoscopic adrenalectomy in patients with adrenal malignancy. J Urol 1997;158:2227.

11. Hamoir E, Meurisse M, Defechereux T. Is laparoscopic resection of a malignant corticoadrenaloma feasible? Case report of early, diffuse and massive peritoneal recurrence after attempted laparoscopic resection. Ann Chir 1998;52:364-8.

12. Lombardi CP, Raffaelli M, Boscherini M, De Crea C, Alesina PF, Traini $\mathrm{E}$, et al. Laparoscopic adrenalectomy in the treatment of malignant adrenal lesions. Tumori 2003;89:255-6.

13. Sarela Al, Murphy I, Coit DG, Conlon KC. Metastasis to the adrenal gland: the emerging role of laparoscopic surgery. Ann Surg Oncol 2003;10:1191-6. 